\title{
La construcción argumentativa de la universalidad de los derechos humanos: el diálogo entre culturas*
}

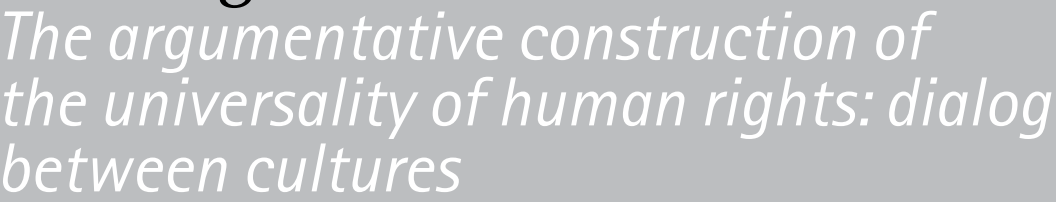

Boris Wilson Arias López ${ }^{* *}$

\begin{abstract}
RESUMEN
La justicia indigena que se constituye en lo particular debe respetar la Constitución y los derechos humanos, los cuales respecto a ésta se constituyen en lo general. Sin embargo, y al mismo tiempo, la interpretación de las normas que hacen al bloque de constitucionalidad, deben tener una interpretación que admita el pluralismo; es decir, que pueda cobijar a diferentes proyectos de vida condicionados culturalmente. La armonización de lo general y lo particular no está dada; debe construirse por consensos a través del diálogo. El presente trabajo hace referencia al diálogo intercultural sobre el cual debe efectuarse la interpretación de los derechos. La decisión de un legislador, funcionario o juez debe elaborarse y recaer en ciudadanos que culturalmente tiene un país, mismos que, en esencia, son diversos y no para ciudadanos ideales. Se analiza el deber de los jueces indígenas en Bolivia de explicar claramente sus decisiones al sancionado, pero también por el resto de jueces ordinarios, pues sin dicha fundamentación se frustraría el diálogo intercultural.
\end{abstract}

PALABRAS CLAVE: Interpretación intercultural, derechos humanos, universalismo.

\begin{abstract}
Indigenous justice that is constituted in this matter must respect the Constitution and Human Rights, which with respect to the latter are in general. Nevertheless, at the same time, the interpretation of the rules that create the constitutionality bloc must have an interpretation that permits pluralism; which means, it shelters different life plans that are culturally conditioned. The harmonization of the general and in this matter then is not given, but must be built by consensus through dialog and not violence. The current work makes reference to intercultural dialog, on which, in my view, the interpretation of rights must be carried out. This is because the decision of a legislator, official or judge must be developed and be of the citizens and the culture that a country actually has, who in essence are diverse; and not for the ideal citizens that a country would like to have.

To this effect, the duty of indigenous judges in Bolivia is to explain their penalty decisions, making them understandable, to the punished person, but also for the rest of the regular judges; because without this rationale, the entire intercultural dialog would be defeated.
\end{abstract}

KEY WORDS: Intercultural interpretation, human rights, universalism.

\footnotetext{
* Recibido: 26 de junio de 2015. Aprobado: 7 de agosto de 2015.

**Profesor en la Universidad de Aquino Bolivia. (borisito55@hotmail.com)
} 


\section{SUMARIO}

1. Introducción a la pretensión de los derechos humanos: ser universales

2. La construcción de la universalidad de los derechos humanos

3. Diálogo intercultural e interpretación de los derechos

4. El deber de fundamentar en la jurisdicción indígena: el caso boliviano

5. Lo dificil de ponerse en los zapatos de otros

6. Conclusiones

\section{Introducción a la pretensión de los derechos humanos: ser universales}

Desde la aparición de la Declaración Universal de Derechos Humanos, luego de la Segunda Guerra Mundial, los derechos humanos pretenden ser reconocidos como universales, de forma que ninguna interpretación impida reconocer que todos tenemos derecho a la vida o a no ser torturados. Sin embargo, y al mismo tiempo, dicha universalidad reclama imponerse a una ingente y diversa cantidad de personas en el mundo, muchas de las cuales a su vez reclaman el derecho humano a su identidad cultural.

En efecto, frente a la abstracción de los derechos humanos como universales, empiezan a surgir minorías indígenas, sexuales, de género, raciales, migrantes, entre otros grupos, los cuales niegan que la identidad de todas las personas deba encajar en un molde universal homogéneo. Estos grupos provocaron el reconocimiento de derechos específicos que consideren sus peculiaridades $;{ }^{1}$ así se ha ahondado en la aguda tensión entre lo general y lo particular.

Una respuesta común a esta paradoja sería aceptar que lo universal de los derechos humanos afectaría al núcleo esencial del derecho, mientras que lo accesorio podría ser afectado por circunstancias materiales, sociales, temporales, culturales. Pero dicha teoría, que pretende resolver la tensión entre lo general y lo particular, ignora el hecho de que mientras más generalizo más me alejo

\footnotetext{
${ }^{1}$ Respecto a la mujer, la Convención sobre la Eliminación de Todas las Formas de Discriminación contra la Mujer; respecto a los niños, la Declaración de los Derechos del Niño, entre otras.
} 
de realidades concretas, ${ }^{2}$ lo cual a su vez no me dice nada sobre cómo resolver problemáticas específicas. ${ }^{3}$

Debe considerarse que, para algunos críticos, los derechos humanos son el resultado de una imposición o colonialismo cultural, de manera que lo universal (los derechos humanos) se habrían construido sobre lo particular (una cultura específica), es decir, la cultura occidental. ${ }^{4}$ Por ello, la Declaración Universal de Derechos Humanos partiría de una concepción del ser humano descontextualizada de la comunidad, ${ }^{5}$ ignorando, en su criterio, que no se debe pensar en el individuo "aislado" sino en el individuo "situado", en el contexto social, cultural, histórico. ${ }^{6}$ Estos críticos creen que cuando se piensa en los derechos humanos como universales se piensa en algo más allá del tiempo. En su criterio, esto no es cierto, pues consideran que cada cultura tiene su propia concepción de derechos, la cual no puede compartirse; por tanto, no existe algo esencial y algo accesorio en los derechos. ${ }^{7}$

\footnotetext{
${ }^{2}$ A decir de Amaya Querejazu Escobar: "el problema es que mientras más universales sean más lejos están del ser humano al que buscan proteger". Querejazu Escobar, AmaYA. "El verdadero poder de los derechos humanos", Revista Estudios de Derecho, vol. 66, No. 147, junio, 2009. [En línea]. Disponible en: https://aprendeenlinea.udea.edu.co/ revistas/index.php/red/article/viewFile/2408/1964

Para Ricardo Sanín Restrepo: "La teoría liberal en su glorificación del modelo individualista niega la dependencia del ser con el mundo, borra artificialmente la alteridad e impone la aberración según la cual el ser es simétrico e idéntico consigo mismo, macabra ilusión que está instalada en nuestra fantasía, según la cual el ser está en pleno control de sí mismo, tiene una claridad superior acerca de sus derechos que el permiten entablar únicamente relaciones instrumentales con otros a partir de la cosificación de los sujetos". Sanin ReSTREPo, Ricardo. Teoría crítica constitucional, Corte Constitucional de Ecuador, Quito, 2011, p. 122.

3 "El derecho borra los vestigios del sujeto en el objeto, lo disemina a lo largo y ancho del complejo jurídico, le asigna un lugar, lo aplana y comprime a formas codificadas". SANin RESTREPO, RICARDO. Teoría crítica constitucional, Corte Constitucional de Ecuador, Quito, 2011, p. 107.

${ }^{4}$ Así, Costas Douzinas afirma que "Los derechos humanos se inauguraron como hitos normativos de un inmenso cambio revolucionario. No obstante, los derechos humanos positivos se han convertido en un mecanismo de defensa que elimina cualquier posibilidad de resistencia y revolución. La erradicación del derecho a la revolución, dentro del paquete de derechos humanos está dirigida a suprimir cualquier transformación radical y se vuelve así la póliza de seguros del orden establecido". Costas, Douzinas. "Prólogo", Teoría crítica constitucional, Corte Constitucional de Ecuador, Quito, 2011, p. 24.

${ }^{5}$ Sin embargo, para Pedro Talavera Fernández se tiene que: "En efecto, si los derechos humanos no son más que los derechos de los 'vencedores'; aquellos que las naciones ricas y desarrolladas dispensan e imponen a los 'vencidos' [...] entonces estariamos ante un potentísimo vehículo de domino y control cultural del mundo [pero] Si bien es cierto que los derechos nacieron en occidente, no es verdad que por ello su valor sea simplemente localista. Es un grave error confundir los orígenes con el valor [...] Los verdaderos valores desafian a las culturas precisamente porque albergan en si mismos una dimensión transcultural". Talavera Fernández, Pedro. "Diálogo intercultural y universalidad de los derechos humanos", Revista IUS, vol. 5, No. 28. [En línea]. Disponible en: http://www.scielo.org.mx/scielo. php?pid=S1870-21472011000200002Etscript=sci_arttext

${ }^{6}$ Para Arthur Kaufmann 'Objeto' del discurso jurídico tan sólo puede ser el hombre, mas no el hombre en cuanto substancia, sino el hombre en su relación con los demás hombres; esto es, el hombre en tanto que persona, con lo cual no se debe entender persona en sentido ético o antropológico, sino ontológico-relacional". Kaufmann, Arthur. Filosofía del derecho, Universidad Externado de Colombia, Bogotá, 2002, p. 372.

7 "La jugarreta liberal de los universales es hacernos creer que la simetría entre significantes y significados políticos es absoluta y singular, es decir que palabras o significantes como democracia, libertad o 'humano' tienen un
} 
Pese a ello, la idea de una sociedad global donde la dignidad de una persona en un rincón del planeta sea igual a la de otra en el otro punto opuesto, pasa por el reconocimiento de iguales derechos para todos. ${ }^{8}$ Entonces, la pretensión de la universalidad de los derechos humanos pasa por la posibilidad de alcanzar un consenso mínimo cultural sobre lo que consideramos "correcto" o "bueno". Dicho debate es de sobremanera importante, en la medida en la que si todo concepto y todo derecho fuera relativo, no podríamos comunicarnos. Al mismo tiempo, tampoco podemos creer que los derechos humanos son dogmas universales que impiden todo debate y cuestionamiento por parte de las minorías. Todo ello devela el reto para la humanidad de distinguir lo que debe ser uniforme y lo que por el principio de igualdad debe tener un trato diferente.

En la manera en la que estamos organizados, el Estado se constituye en garante de la unidad y de la diversidad étnica y cultural, y por tanto de las leyes y los reglamentos. Por su parte, las sentencias se encuentran en la tensión entre lo general que nos une a la humanidad y lo particular que nos hace diferentes. En este contexto, el presente trabajo parte de la idea de que lo que consideramos como derechos humanos, por ejemplo un debido proceso, no es un punto de partida, sino de llegada.

\section{La construcción de la universalidad de los derechos humanos ${ }^{9}$}

Para que la construcción de los derechos humanos pueda admitir la diferencia étnica-cultural, debería tomarse en cuenta lo siguiente. Los pueblos incluso antiquísimos no son estáticos, sino que evolucionan. Ello implica reconocer que toda cultura es histórica, compleja y dinámica. Pero además reconocer que contienen en sí mismas principios y fuerzas contradictorias, lo cual, a su vez, provoca admitir que son criticables o susceptibles de ser criticadas. ${ }^{10}$ En este

solo significado correspondiente posible pero, sin embargo, la segunda parte del truco es fijar ese significado retrospectivamente". Sanin ReSTREPO, Ricardo. Teoría crítica constitucional, Corte Constitucional de Ecuador, Quito, 2011, p. 124.

${ }^{8}$ El secretario general de la onu Boutros Ghali en su discurso inaugural a la Conferencia Mundial de los Derechos Humanos de 1993 sostuvo: "Los derechos humanos constituyen el lenguaje común de la humanidad gracias al cual todos los pueblos pueden comprender simultáneamente a los demás y escribir su propia historia. Por definición, los derechos humanos son la última norma de cualquier política".

${ }^{9}$ En la filosofía politica se suele diferenciar entre los denominados liberales como Rawls, Habermas o Kymlicka, basados en mínimos como la libertad e integridad personal, y en el otro extremo a los denominados comunitaristas, como Sandel, Taylor, MacIntyre y Walzer. Sin embargo, debe considerarse que si bien Rawls y Habermas son liberales, Rawls deja lo cultural en la vida privada a través del denominado "velo de la ignorancia", lo cual le da imparcialidad a su tesis; la acción comunicativa de Habermas, por otro lado, parte de condiciones ideales de dialogo. Hay muchas diferencias entre ellos, de ahi que el presente trabajo no parta de un postulado teórico en particular.

${ }^{10}$ Para Pedro Talavera "afirmar a priori el valor de todas las culturas no puede conducir a una especie de relativismo cultural que paralice e imposibilite la crítica moral hacia ellas. Seria gravemente erróneo concebir las culturas 
contexto, la relación entre culturas puede implicar una influencia positiva si existe entre ellas un diálogo sincero y abierto. ${ }^{11}$

Pongamos como ejemplo a José Ortega y Gasset, quien para explicar la conformación de una sola nacionalidad europea, recordó que la idea de fronteras naturales en Europa entre los diferentes países surgió del pensamiento mágico (y por tanto primitivo) donde la nación era un destino dado por los dioses. ${ }^{12}$ En realidad y objetivamente, sin embargo, para los pueblos europeos primitivos la famosa frontera natural no era otra cosa que el estorbo de un pueblo para seguir creciendo, sea un río u otro pueblo.

Dicho autor sostuvo que la construcción de las naciones europeas ${ }^{13}$ se hizo negando el pasado. Es decir, las tribus que en su momento se consideraban nación fueron negadas por la comarca que también se consideraba nación, y que a su vez fue negada por la región considerada en su momento nación hasta la formación de los estados europeos, que hoy se consideran nación. Sobre lo expuesto, José Ortega y Gasset concluyó que no existió una nación como tal, pues ésta siempre fue una creación histórica y por tanto eventual. Ello implica que lo que consideramos como una nación siempre puede ser diferente, pues lo que entendemos por nación se va modificando permanentemente. Entonces, no sólo es pasado, sino futuro, de ahí que en su criterio podía hacerse de Europa una sola nación.

Pero además, en este contexto debe recordarse que el origen de las culturas se da por la necesidad de los seres humanos de compartir y colaborarse, porque no podemos vivir solos, máxime con los avances tecnológicos con los que contamos hoy en día, los cuales ponen fin a las fronteras nacionales. La necesidad de convivencia provoca la necesidad de acuerdos mínimos para intercambiar productos, manejar la migración o las políticas internacionales, de los cuales es posible extraer un derecho común internacional como ya va sucediendo. Por ejemplo, basta pensar que dos países tan disímiles en política internacional como Venezuela y Estados Unidos intercambian a diario productos y servicios.

como monumentos petrificados e inmodificables. Las grandes y verdaderas culturas son un mundo vivo $y$, aunque lentamente, en continua evolución y desarrollo". Talavera Fernández, Pedro. "Diálogo intercultural y universalidad de los derechos humanos", Revista IUs, vol. 5, No. 28. [En línea]. Disponible en: http://www.scielo.org.mx/scielo. php?pid=S1870-21472011000200002\&tscript=sci_arttext

11 "Los representantes de las comunidades indigenas deben estar dispuestos a abandonar reglas o principios de comportamiento si, dadas las circunstancias actuales, ellos contribuyen a aumentar su vulnerabilidad" (GARZón VALDÉS, Ernesto. El problema ético de las minorias étnicas. [En línea]. Disponible en: biblio.juridicas.unam.mx/libros/4/1658/8.pdf ${ }^{12}$ Para Ortega Gasset: "Son, se dice 'fronteras naturales', y con su 'naturalidad' se significa una mágica predeterminación de la historia por la forma telúrica" (ORTEGA y GASSET, JosÉ. La rebelión de las masas, Espasa, España, 2005, p. 192.

13 "Para explicarnos cómo se han formado Francia y España, suponen que Francia y España preexistían como unidades en el fondo de las almas francesa y españolas. iComo si existiesen franceses y españoles originariamente antes de que Francia y España existiesen!" ORtega y Gasset, José. Op. cit., p. 192. 
Estos países utilizan a los derechos humanos para recriminarse mutuamente; por consiguiente, en dicho debate, si bien no existe una idea común sobre lo que significan los derechos humanos, existe la pretensión de un discurso común sobre ellos, lo que per se ya es un gran avance.

Todo ello implica reconocer que la realidad cambia, pero al mismo tiempo que el ser humano no es un ser acabado e inmutable; de ahí que es posible construir de manera consciente una ciudadanía universal conformada por valores comunes, fruto del diálogo intercultural al que podemos llamar derechos humanos, los cuales tampoco pueden ser inmutables y acabados.

Ahora bien, si reconocemos que el ser humano no puede conocer algo de manera definitiva y para siempre, que en todo momento existe la posibilidad de equivocarse $\mathrm{y}$, por tanto, toda verdad humana es provisional hasta que no sea desmentida, ${ }^{14}$ se comprende entonces el motivo por el cual ayer el derecho a integrarse de los pueblos indígenas se transformó en el derecho a la identidad cultural. ${ }^{15}$ El derecho de transexuales a ser tratados médicamente se transformó en el derecho a la identidad sexual. Esto muestra que toda conclusión sobre qué es un derecho es provisional, y que luego puede corregirse o cambiarse. Es decir, hace que la idea de universalidad de los derechos humanos sea una pretensión más que algo concreto; aspecto que explica la naturaleza "progresiva" de los derechos humanos.

Entonces, si bien la universalidad de los derechos humanos implica contenidos mínimos a la dignidad humana, que independientemente del origen cultural todo ser humano los aceptaría, ello sólo podría darse por el diálogo intercultural y de manera provisional. Esto provoca que deba prestarse atención a las condiciones y sinceridad de dicho diálogo.

Sin embargo, el problema de aceptar un diálogo intercultural parecería implicar que se aceptan dos cosas contradictorias; por una parte, a dos culturas cuyos valores parecen totalmente relativos que además y por tanto deben estar en un mismo nivel -no como culturas dominantes y dominadas-; ${ }^{16}$ por

\footnotetext{
${ }^{14}$ El principio de falsabilidad fue desarrollado por Popper. Pretendía referir a una teoría que cuando no es refutada como "falsa" por los hechos queda como una verdad "provisional" sin que nunca pueda tenérsela como verificada del todo. Popper, Karl. La Lógica de la Investigación Científica, Tecnos, Madrid, 1967.

${ }^{15}$ Por ejemplo, en materia indígena, el Convenio 107 de la olT, cuya visión era integracionista y asimilacionista al grado de reconocer el derecho de las minorías a integrarse a las mayorias, fue sustituida por el Convenio 169 de la оाт, que defendió en contrapartida el derecho de los pueblos indigenas a mantener su propia cultura.

${ }^{16}$ A decir de Boaventura de Sousa Santos: "Este constitucionalismo se distingue del constitucionalismo moderno en varias características. Primero, en la equivalencia entre lo simultáneo y contemporáneo. Una de las grandes características de la modernidad fue separar simultaneidad de contemporaneidad. ¿Por qué? Porque puso una flecha de progreso; los que van delante están en el progreso, son avanzados, mientras todos los otros son atrasados. Es por eso que los países menos desarrollados no pueden ser nunca en nada más desarrollados que los desarrollados, porque la lógica de la flecha del tiempo impide esa posibilidad. Sin embargo, la idea de simultaneidad sin contemporaneidad expresa situaciones cotidianas. Cuando un campesino se encuentra con un ejecutivo del Banco Mundial el encuentro es simultáneo, pero no ocurre entre contemporáneos. El campesino es un residual, es un atrasado; el ejecutivo
} 
otra, que dicho diálogo exige un mínimo de acuerdo que lo permita. ${ }^{17}$ En otras palabras, para que exista diálogo se requiere algo común. Sin embargo, ello puede negar las diferencias de los dialogantes, pues si una parte defiende frente a la otra el canibalismo, existirá necesariamente un grado de imposición para que ambas culturas puedan comunicarse. En ese caso no todo será diálogo; habrá algo impuesto.

Considero que para resolver el dilema existe un mínimo provisional entre dichas culturas fruto de la experiencia histórica emergente del sufrimiento y la desgracia humana. ${ }^{18}$ A su vez, también puede discutirse en el marco del resto de las reglas de debate, de manera que una verdad provisional se sostiene y garantiza por las otras verdades provisionales. No puedo decir que en un pueblo indígena no debería respetarse el derecho a presentar pruebas de descargo, y alegar al mismo tiempo que esta situación no lesiona el derecho a la defensa y la garantía del debido proceso. En todo caso y si esto sucede en un pueblo indigena, es dicha minoría la que debe demostrar a la humanidad cómo y en qué medida el hecho de que no pueda presentar pruebas de descargo resulta racional en ciertos casos, de forma que la mayoría pueda reformular el postulado universal.

Ese mínimo provisional es lo que permite a la comunidad internacional y a los Estados (como garantes de la convivencia pacífica) que impongan límites a la identidad cultural, sea occidental o indígena. Sólo bajo esa consideración puede concebirse de manera auténtica al pluralismo como un nexo que relaciona a lo general con lo particular. ${ }^{19}$ Además, a decir de Arthur Kaufmann, se reitera que el mínimo que permite el diálogo intercultural, y que llamamos derechos humanos, sólo puede estar constituido por aquello que nos hace

\footnotetext{
del Banco o el ingeniero de la agroindustria es el progreso, es el avanzado. Tenemos simultaneidad, pero no contemporaneidad. El constitucionalismo intercultural y plurinacional, está haciendo, de diferentes maneras, una equivalencia entre lo que es simultáneo y lo que es contemporáneo; cada uno a su manera, pero contemporáneos al fin". De Sousa Santos, Boaventura. La reinvención del Estado y el Estado plurinacional. [En línea] Disponible en biblioteca.clacso.edu.ar/ar/libros/osal/osal22/D22SousaSantos.pdf

${ }^{17}$ Como se dijo, un relativismo absoluto impediria todo tipo de comunicación y diálogo.

${ }^{18}$ La Corte Constitucional de Colombia en la sentencia T-903/09 dedujo el principio de "a mayor conservación de la identidad cultural, mayor autonomia" de la siguiente manera: "el 'núcleo duro' es un límite absoluto que trasciende cualquier ámbito autonómico de las comunidades indígenas. Cualquier decisión que desconozca el derecho a la vida, lesione la integridad de una persona o transgreda las prohibiciones de tortura y servidumbre está constitucionalmente prohibida, aunque la evaluación de una eventual vulneración, especialmente en cuanto a la integridad personal y el debido proceso debe realizarse a la luz de la cultura específica en que se presenten los hechos. Los [demás] derechos fundamentales constituyen un límite que debe establecerse a través de un ejercicio de ponderación en cada caso concreto [...] En estos conflictos, sin embargo, los derechos de la comunidad gozan de un peso mayor, prima facie, en virtud al principio de 'maximización de la autonomia'".

${ }^{19}$ De ahí que: "el pluralismo tiene que ser entendido como algo intermedio entre universalismo y particularismo". CÉspedes Argandoña, Guido. "La posnación y el pluralismo analógico", en Pluralismo jurídico e interculturalidad, IdEl, Cochabamba, Bolivia, p. 65-98.
} 
infelices -el hambre, la tortura, la humillación-, pero nunca por lo que consideramos felicidad. Cada uno tiene una idea diferente de lo que le hace feliz. ${ }^{20}$ Lamentablemente entonces lo que entendemos por derechos humanos en el diálogo intercultural por regla general se construye sobre la desgracia, la humillación y el sufrimiento humano.

\section{Diálogo intercultural e interpretación de los derechos}

La coexistencia de los derechos de por sí es conflictiva. En el ámbito cultural, el pluralismo impele a reconocer igual protección a los derechos, lo cual impide establecer un orden jerárquico valorativo a priori. Pero, además, el diálogo intercultural impulsa a realizar una interpretación intercultural de los derechos, ${ }^{21}$ que busque como resultado su coexistencia, entre ellos el derecho a ser diferente. $^{22}$

En este sentido, el diálogo intercultural busca que los pueblos del mundo alcancen consensos mínimos, por ello ni las Constituciones, ni los derechos humanos pueden ser todo consenso; por tanto, siempre existe algo de imposición. ${ }^{23}$ Sin embargo, y al mismo tiempo, es necesario que dichos instrumentos normativos tengan una interpretación que permita el debate y la coexistencia

\footnotetext{
${ }^{20} \mathrm{~A}$ decir de Arthur Kaufmann, "no es posible universalizar la felicidad, a menos que se conciba vacía de contenido". Kaufmann, Arthur. Filosofía del derecho, Universidad Externado de Colombia, Bogotá, 2002, p. 325.

${ }^{21}$ Así, la Corte Interamericana de Derechos Humanos, en la sentencia de Fondo, Reparaciones y Costas dentro del caso Comunidad indigena Yakye Axa Vs. Paraguay de 17 de junio de 2005, efectuó una interpretación amplia del derecho a la propiedad reconocido por el artículo 21 de la Convención Americana sobre Derechos Humanos. Abarcaba incluso la propiedad indigena colectiva. Sostuvo que: "En otras oportunidades, tanto este Tribunal como la Corte Europea de Derechos Humanos han señalado que los tratados de derechos humanos son instrumentos vivos, cuya interpretación tiene que acompañar la evolución de los tiempos y las condiciones de vida actuales. Tal interpretación evolutiva es consecuente con las reglas generales de interpretación consagradas en el artículo 29 de la Convención Americana, así como las establecidas por la Convención de Viena sobre el Derecho de los Tratados". En este sentido, la interpretación "conforme a los tratados de derechos humanos" debe efectuarse considerando el contexto cultural,

${ }^{22}$ Nos recuerda Ferrajoli que: "La prohibición de portar el velo (por ejemplo en Francia, en determinados lugares) equivale a la imposición de una cultura, al igual que la obligación de llevarlo, que es contraria a la libertad y al derecho de cada persona para vestirse como quiera. Lo que, en efecto, justifica la prohibición o el castigo (obviamente con base en pruebas) no es ya el portar el velo, sino la eventual violencia o amenaza que hay detrás de esa práctica. Derecho a llevar el velo, y prohibición y castigo por su eventual imposición coactiva, son dos caras de la misma medalla, ambas en garantía de la libertad individual, más que religiosa, de la persona: el primero en tutela de la persona que lleva el velo por su propia y espontánea libertad, la segunda en tutela de la persona obligada a llevarlo en contra de su voluntad. Por el contrario, la prohibición del velo, paradójicamente por parte de un país como Francia que se proclama laico, equivale a la juridificación de una concepción, de una ética y de una cultura laica, y a su imposición por medio del derecho". FERRAJoL, LuIGI. Universalismo de los derechos fundamentales y multiculturalismo. [En linea] Disponible en: www.juridicas.unam.mx/publica/rev/boletin/cont/122/inf/inf25.htm

${ }^{23} \mathrm{Al}$ respecto, considero que un diálogo intercultural presupone una institucionalidad fundada en mínimos legales, como la prohibición de la tortura o la prohibición del esclavismo, los cuales, incluso si llegan a beneficiar a las partes dialogantes, les pueden resultar impuestas.
} 
de variados proyectos de vida. Esto impele a aceptar un "margen de apreciación" en dichos textos normativos que admita la diferencia. ${ }^{24}$

Pero, además, el diálogo intercultural, para ser un "diálogo" requiere que todas las culturas, incluida la occidental, se encuentren en un plano de igualdad material y no sólo formal. Ello permitirá que lo que consideramos general (es decir, los derechos humanos) no sea lo particular con vestimenta de lo general, y que en lo futuro lo particular pueda en algún momento volverse lo general, sin necesidad de guerras internas y muertos. Pese a ello, debe recordarse siempre que lo general lo es justamente porque puede soportar lo particular; lo contrario generará intolerancia.

Asimismo, el diálogo intercultural sobre el cual se desarrolla la interpretación intercultural busca que, con el tiempo, el intercambio de opiniones y la propia coexistencia de los pueblos permitan consolidar una cultura de un derecho mínimo de derechos humanos. Debe recordarse que los derechos tienen una dimensión cultural, de donde surge su capacidad para integrar al colectivo, en este caso, a un colectivo universal, pues ahí es donde se encuentra la meta más importante de los derechos humanos. ${ }^{25}$

En ese marco, emerge la responsabilidad de los jueces occidentales e indígenas de respetarse, puesto que ellos son garantes de lo universal y de lo particular. Por ejemplo, para respetar la diferencia se reconoce a la justicia indígena que permite efectivizar el derecho de acceso a la justicia conforme las especificidades culturales indígenas, respetar al juez natural, pues el juez ordinario no tiene suficientes conocimientos contextuales para resolver sus problemáticas o para la atención de una defensa adecuada. Al mismo tiempo, el juez indígena se vuelve garante de lo general puesto que debe realizar control de convencionalidad.

Un juez que forma parte de una comunidad también debe recordar que los pueblos deben ser tolerantes y respetar el pluralismo, para que cuando su pueblo no lo pueda hacer, sea él quien, en calidad de occidental o indígena, pueda apartarse de su propia cultura y el criterio mayoritario, haciendo respetar el derecho mínimo que hace al diálogo intercultural. ${ }^{26}$

\footnotetext{
${ }^{24}$ Ante un conflicto entre la ley y la costumbre en un pueblo indigena, la Corte Constitucional de Colombia sostuvo que a mayor conservación de sus usos y costumbres es mayor la autonomía. En este sentido, las leyes rigen sobre las costumbres sólo si protegen un valor constitucional superior al principio de diversidad étnica y cultural, siendo los derechos humanos un mínimo que una al Estado colombiano con el resto de los pueblos.

${ }^{25} \mathrm{Al}$ respecto, "es evidente que una cultura no puede ser enjuiciada utilizando como unidad de medida otra cultura [...] Sin embargo, el error del relativismo consiste en presentar las culturas como 'universos cerrados de experiencia que no remiten a nada más que a si mismos', cuando en realidad las diferentes culturas serian manifestaciones múltiples de nuestra común humanidad. Puede decirse que la humanidad proporciona un criterio de referencia común, transcultural con base en el cual se pueden evaluar los fenómenos culturales concretos". Talavera Fernández, Pedro. Op. cit.

${ }^{26}$ Recuerda Manuel Atienza que: "Hace pocos dias un tribunal español condenó a una mujer mauritana, porque
} 


\section{El deber de fundamentar en la jurisdicción indígena: el caso boliviano}

Imaginemos un caso donde una persona originaria de un pueblo indígena es expulsada de su comunidad por ser khari khari o liquichiri, brujo que produce inconsciencia de sus víctimas para luego quitarles cierta grasa corporal, que provoca que enfermen y mueran. Entonces, este procesado acude a la jurisdicción ordinaria manifestando que si bien existe ese tipo de brujos, en la comunidad no se demostró con prueba alguna que fuera uno de ellos: ¿Cómo debería resolver el caso la justicia constitucional?

Imaginemos además que esta persona solicitó que se considere el deber de fundamentar las resoluciones, ya que para la jurisdicción ordinaria es clara la jurisprudencia constitucional cuando establece: "toda autoridad que conozca de un reclamo, solicitud o que dicte una resolución resolviendo una situación jurídica, debe ineludiblemente exponer los motivos que sustentan su decisión". ${ }^{27}$ Sin embargo, para los juzgadores indigenas no existe un criterio uniforme al respecto. Muchos consideran que no tienen la obligación de fundamentar, ni de dejar resoluciones escritas porque sus antecesores no lo hacían, ello incluso en casos donde se aplica la sanción de expulsión definitiva de la comunidad.

Ahora bien, para proponer una respuesta al caso hipotético que acabo de plantear, haré una breve referencia a la construcción de la racionalidad y su relación con la fundamentación de las resoluciones, para luego sustentar que sí existe dicha obligación.

Antiguamente se pensaba que el universo tenía una estructura necesaria. Por ejemplo, si suelto una piedra en el aire, la misma no puede dejar de caer. Entonces, un juez que resolvía una problemática sometida a su competencia conforme a dicha realidad dictaba una resolución racional. La idea de un mundo racional y de que este podía conocerse con la experimentación provocó que:

- Se generara la idea de que el pensamiento podía matematizarse, es decir, podían redactarse leyes eternas.

esta última había obligado a una hija de 14 años a casarse y tener relaciones sexuales con un hombre de 40 años. La mujer y varios compatriotas suyos reclamaron ante las puertas del juzgado 'respeto hacia sus tradiciones', esto es hacia los valores característicos de su forma de vida. ¿Sería aceptable que los jueces hubiesen justificado su decisión esgrimiendo, como razón última, que la libertad personal (de la chica) era el valor que debía prevalecer aquí simplemente porque es el predominante en la comunidad jurídica española? ¿No supone eso un reconocimiento de que, si el juicio se hubiese celebrado en Mauritania (y, efectivamente, los matrimonios forzados formaran parte de la cultura alli predominante), entonces la decisión justificada habría sido otra?" Atienza, Manuel. "Sobre la única respuesta correcta", Revista Jurídicas, vol. 6, No. 2, Colombia, 2009, pp. 13-26.

${ }^{27}$ Bolivia, Tribunal Constitucional, sentencia constitucional 1326/2010-R de 20 de septiembre. 
- Se concretara un concepto de derecho no sujeto a alguna sociedad en particular ni a cambios.

- Se separara a la ciencia de la teología y esta última dependiera estrictamente de la fe.

Este tipo de razonamiento jurídico provocó que cuando se impugnaba el régimen normativo civil, donde se determinaba la administración de bienes conyugales a favor del hombre en desmedro de la mujer, se estableciera por el juez que era natural, lógico, necesario y por tanto justo dicho régimen normativo en la medida en que, a su criterio, el hombre y la mujer tenían esencias diferentes. Entonces, respecto a la mujer era el hombre quien, por naturaleza, administraba mejor los bienes materiales.

Luego, al observar dicha subjetividad, se pensó que lo racional era lo que seguía o era producto de un método racional. En lo judicial, se empezó a prestar atención a la tramitación de los procesos judiciales. El juez llegaba a una sentencia justa si seguía a rajatabla el procedimiento establecido en la ley. En lo teórico, para los positivistas la neutralidad del derecho estaba en el procedimiento de creación del derecho, mientras que en la argumentación jurídica lo racional se contenía en la subsunción, cuyo elemento de corrección era la lógica. El proceso se depuró de creencias religiosas y se dejó atrás en lo procesal a las ordalías o juicios de Dios. ${ }^{28}$ Pese a ello, es posible aceptar que un juez, a pesar de seguir el procedimiento legal, pueda equivocarse; es decir, seguir un procedimiento no asegura la verdad material.

Posteriormente, se diferenció la ley natural de la ley humana, debido a que ésta última tiene algo de eventual. Entonces, en el ámbito del derecho se pensó que lo racional no venía de la realidad. Así, Perelman creyó que lo racional se determinaba por el auditorio en el cual se exponía; si ese público que es cultural y temporal se modifica, también cambia la idea de lo que es racional. Para él, todo juez escribe una sentencia pensando en las partes procesales y en el público que leerá la decisión. Entonces no es racional por decir la verdad, sino por convencer al perdedor sobre la rectitud de la decisión. Dicha teoría, sin embargo, tampoco explica cómo podríamos llegar a consensos sobre lo racional, si el público se compone de personas demasiado diversas.

Entonces, hoy día surge la idea predominante respecto a que lo racional no puede alcanzarse por la mera reflexión individual, sino a través del diálogo. Es decir, el diálogo nos dice cuál es un buen o mejor argumento. En un espacio donde todos somos diferentes y cada uno tiene derecho a ser y pensar diferente,

\footnotetext{
${ }^{28}$ Pese a ello, se mantuvieron en los tribunales fuertes creencias religiosas como juramentos, crucifijos, entre otros.
} 
lo razonable y lo correcto no puede ser impuesto, sino que tiene que ser fruto del intercambio de opiniones e ideas..$^{29}$ En otras palabras, un juez que pretende tomar una decisión racional debe intentar tomar en cuenta todos los aspectos negativos o positivos de su decisión. Para eso, necesita saber y escuchar más, incluso sobre aquello que ataca o se contrapone a sus creencias.

En este contexto, considero que si una cultura se relativiza con otra, por ejemplo, si los indígenas relativizan a la cultura occidental, sucede al mismo tiempo lo contrario. Si un juez indígena no fundamenta su decisión en los hechos, estaría encerrando su cultura en sí misma e impediría el diálogo intercultural y toda ulterior revisión de la justicia constitucional o interamericana.

Veamos la SCP 2076/2013, dictada debido a que dentro de un amparo constitucional la accionante sostuvo que habiendo llegado un canal de televisión a su comunidad para ejemplificar la aplicación de la justicia indígena, utilizó vestimenta de autoridad indígena, motivo por el cual fue expulsada por tres años de toda actividad comunal en atención al artículo 7 inciso $d$ del Reglamento Interno de la Comunidad, el cual indicaba como falta: "Portar la vestimenta originaria en acontecimientos importantes, mientras dure la función”.

El Tribunal Constitucional concedió la tutela entendiendo que si bien la resolución sancionatoria impugnada se basó en normativa local, no explicó a la accionante por qué debía imponerse una sanción tan severa como la expulsión de actividades comunales por el término de tres años, ignorándose por la comunidad indígena que toda sanción debe regirse por los principios de razonabilidad y proporcionalidad. Esto implica una fundamentación mínima que le permita comprender a la accionante y a la justicia constitucional por qué esa sanción tan severa es en criterio del pueblo indígena razonable o proporcional.

En dicho caso, el Tribunal Constitucional explicó que: "las resoluciones deben ser ante todo claras e inteligibles, más que abundantes, deben informar de manera efectiva al afectado sobre los aspectos más relevantes de la resolución, permitiéndole asumir un conocimiento cabal y suficiente acerca de las razones que sustentan la decisión".

En otra decisión, dentro de otro amparo constitucional que concluyó en la sentencia SCP 0033/2015-S3, los accionantes manifestaron que los comunarios ingresaron a sus sembradios de quinua y los desalojaron, por lo que acudieron a la policía y a la jurisdicción penal. Tras ello, se emitió resolución comunitaria de 31 de marzo de 2013, que determinó expulsarles de manera

\footnotetext{
${ }^{29}$ Es decir "la garantía auténtica del consenso radica en las condiciones de la comunicación, en que todas las personas potencialmente afectadas tienen, de igual manera, la oportunidad de una natural toma de posición en un coloquio". Hofmann, Hasso. Nuevos desarrollos en la filosofía del derecho. [En línea]. Disponible en: http://www. juridicas.unam.mx/publica/librev/rev/jurid/cont/29/cnt/cnt23.pdf
} 
definitiva; se les ordenó el desalojo y la pérdida definitiva de sus terrenos. El Tribunal Constitucional identificó dos problemáticas: 1) Sobre medidas de hecho, y 2) Sobre la determinación comunitaria de 31 de marzo de 2013 de expulsión defınitiva.

Sobre las medidas de hecho denunciadas, es decir los desalojos ilegales y las agresiones de las cuales habrían sido víctimas, el órgano de control de constitucionalidad evidenció que tras ser desalojados los accionantes acudieron a la policía y al delegado del Gobierno Departamental, quienes también fueron amenazados y expulsados del lugar. Se retuvo a los accionantes, a quienes agredieron física y verbalmente. Dicho actuar de los demandados al margen de un procedimiento y el respeto de las garantías procesales se entendió como justicia por propia mano y no el ejercicio de justicia indígena. ${ }^{30}$

Respecto al segundo punto, en la resolución comunitaria de 31 de marzo de 2013, que determinó la expulsión definitiva de los accionantes, el órgano de control de constitucionalidad recordó que para activar la competencia de la jurisdicción indígena en Bolivia deben concurrir tres ámbitos:

- El ámbito de vigencia personal, respecto al cual el artículo 191-II-1 de la Constitución establece que: "están sujetos a esta jurisdicción los miembros de la nación o pueblo indígena originario campesino". Dicha membrecía se determina por el vínculo "particular" ${ }^{31}$ que une a los miembros de una nación o pueblo indígena originario campesino.

- El ámbito de vigencia territorial, es decir, la justicia indígena: "se aplica a las relaciones y hechos jurídicos que se realizan o cuyos efectos se producen dentro de la jurisdicción de un pueblo indígena originario campesino". ${ }^{32}$ De forma que no alcanza a migrantes que individual y voluntariamente abandonaron sus espacios geográficos y se sometieron a la competencia de la justicia ordinaria.

- El ámbito de vigencia material, referido por el artículo 191-II-2 de la Constitución, que establece que la jurisdicción indígena originaria campesina "conoce los asuntos indígenas originarios campesinos de conformidad a lo establecido en una ley de Deslinde Jurisdiccional". Dicha norma hace referencia a "asuntos" porque en las

\footnotetext{
${ }^{30}$ En la sentencia constitucional 1234/2013-L se sostuvo: "en el Estado Social de Derecho Plurinacional Comunitario no se admite la defensa propia del derecho o la denominada justicia por mano propia, al contrario advierte que los desobedientes serán pasibles de imponérseles las sanciones que establezca la ley; concediendo, a las víctimas, el derecho a la indemnización, reparación y resarcimiento de daños y perjuicios en forma oportuna".

${ }^{31}$ Boulvia. Constitución Politica del Estado, 2009, artículo 190-I.

${ }^{32}$ Bolivia. Constitución Politica del Estado, 2009, artículo 191-II-3.
} 
comunidades indígenas no se diferencian materias, como las civiles, penales, etcétera. ${ }^{33}$

Hecha dicha precisión se analizó la resolución comunitaria del 31 de marzo de 2013. En ella se estableció que el accionante no sería comunario; con ello incurrió en una incongruencia en la medida en la que si no sería miembro de dicha comunidad entonces ellos no tendrían competencia para determinar su expulsión y que: "para que las determinaciones de la justicia indígena sean respetadas es necesario que muestren, en la resolución de los casos, que concurren los ámbitos personal, material y territorial, explicando que según sus normas y procedimientos propios están juzgando problemas producidos bajo su jurisdicción y competencia”.

Por otra parte y ya en el análisis de fondo, se observó que la resolución impugnada, tras referir los antecedentes de hecho, pasó directamente a declarar la expulsión definitiva ignorando el deber de fundamentar. Se entiende que: "las autoridades demandadas omitieron ese deber limitándose a señalar que se cometieron faltas graves, pero sin mostrar que la expulsión está prevista en sus estatutos y normas y cómo las supuestas faltas provocan que deba adoptarse una medida tan drástica como la expulsión”. Dicha omisión argumentativa vulnera el debido proceso.

Como se vio, la justicia indígena también debe aplicar e interpretar de manera intercultural la Constitución y los tratados de derechos humanos, evitando una interpretación etnocentrista y monocultural. Un pueblo indígena se desenvuelve en un contexto poblacional mayor con el cual debe coexistir; por tanto, se debe encontrar argumentativamente unos mínimos que temporalmente podemos llamar universales. ${ }^{34}$ En consecuencia, considero que si una norma indígena estableciera que sus resoluciones no necesitan fundamentación dicha norma sería inconstitucional, pues impediría el diálogo intercultural.

Entonces, volviendo al hipotético caso del khari khari o liquichiri, siendo que no se debate sobre su existencia sino sobre si el accionante es o no un brujo, es decir sobre si existe o no suficiente material probatorio, considero que les corresponde a los jueces indígenas explicar en su resolución la importancia del caso para dicha población y las pruebas que en su criterio acreditarían lo denunciado. ${ }^{35}$ El Tribunal Constitucional debe dejar sin efecto la decisión si

\footnotetext{
${ }^{33}$ Dicha ley No. 073 se promulgó en fecha 29 de diciembre de 2010.

${ }^{34}$ Para Guido Céspedes: "los valores universales son contacto entre las diferentes culturas". Céspedes Argandoña, Guido. "La posnación y el pluralismo analógico", en Pluralismo jurídico e interculturalidad, IDEI, Cochabamba, Bolivia, p. 93. ${ }^{35}$ Debe recordarse que los métodos de interpretación clásicos no necesariamente pueden aplicarse en la justicia indigena. En este sentido, a veces no puede utilizarse el método gramatical porque no se interpretan solamente
} 
la misma no tiene una mínima fundamentación. Dicho reenvío permitirá que sea el propio pueblo indígena, en ejercicio de su autonomía, quien interprete y aplique su propio derecho, pero al mismo tiempo lo haga de manera racional.

Cuando no se fundamenta una resolución, se impide un control adecuado de los mínimos constitucionales resguardados por la Constitución y los tratados internacionales de derechos humanos. Para pedir comprensión los otros, al mismo tiempo se debe explicar por qué se considera que se tiene la razón, lo contrario - no fundamentar- implicaría, por un lado, que no se respeta al procesado, el cual no tendría derecho a conocer el motivo de su castigo, y por otro que no se respeta al resto de jueces que no comparten la misma cultura y por tanto no entenderán la razón de la decisión. La convivencia no es sinónimo de coexistencia, puesto que la convivencia está construida; por ello no puede ser fruto de la imposición, sino de buenas razones. ${ }^{36}$

\section{Lo difícil de ponerse en los zapatos de otros}

Cuenta Heródoto, citando a Píndaro, que Darío llamó a los griegos y preguntó si se comerían a sus padres muertos. Ellos le respondieron que no harían algo tan grotesco. Luego llamo a los egipcios calatias, que justamente comían a sus padres luego de muertos, a quienes les preguntó si tras la muerte de sus padres quemarían sus cadáveres, ellos respondieron que no harían algo tan desagradable. ${ }^{37}$ Entender al otro implica ponerse en sus zapatos, pero no es fácil hacerlo.

normas escritas, sino costumbres, tradiciones. A veces no puede usarse el método lógico, pues las concepciones del mundo pueden no responder a una racionalidad occidental. Respecto al método histórico, debe recordarse que coexisten diferentes contemporaneidades; respecto al método sistemático, debe recordarse que el sistema jurídico encierra más contradicciones que coincidencias. Por ello, en este tipo de casos puede no resultar admisible el método de la subsunción.

${ }^{36}$ No resulta suficiente el reconocimiento y cumplimiento de los derechos humanos, sino que además deben resultar legítimos a las minorias étnicas, porque: "supongamos que un individuo, por temor a las sanciones, se abstiene de llevar adelante una forma de vida tipificada como disvaliosa, pero nunca llega a suscribir las creencias en que se basa tal juicio de valor negativo. En este caso, no podremos concluir que su vida ha mejorado, o que es superior a la que hubiera tenido de no aplicarse la política en cuestión. La conclusión de que ha habido una mejora en el bienestar crítico del agente sólo podría sostenerse en caso de que éste realmente llegara a suscribir las creencias en las que se basa esa acción del Estado". GarReta Leclerco, Mariano. "Neutralidad estatal, libre adhesión y bienestar crítico", Análisis filosófico, vol. 25, No. 2, 2005, pp. 165-199. [En línea]. Disponible en: http://www.scielo.org.ar/scielo. php?script=sci_arttext\&tpid=S1851-96362005000200004\&tIng=es\&tnrm=iso

${ }^{37}$ Herodoto narró lo siguiente: "Durante el reinado de Darío, este monarca convocó a los griegos que estaban en su corte y les preguntó que por cuánto dinero accederian a comerse los cadáveres de sus padres. Ellos respondieron que no lo harian a ningún precio. Acto seguido Darío convocó a los indios llamados Calatias, que devoraban a sus progenitores, y les preguntó, en presencia de los griegos, que seguian la conversación por medio de un intérprete, que por qué suma consentirian en quemar en una hoguera los restos mortales de sus padres: ellos entonces se pusieron a vociferar, rogándole que no blasfemara". HeRódoto. Historia III (Talía), Gredos, Madrid, 2000, p. 87. 
Nuestra identidad surge cuando uno se compara con los otros y se ve diferente. ${ }^{38}$ Aquello que en primera instancia nos enriquece puede llevarnos a hacernos una idea cerrada de nosotros mismos, de cómo somos y seremos, provocando que actuemos en consecuencia a dicha idea, ignorando que nuestra identidad, incluida la "cultural", no está hecha, sino que se va haciendo. Mi "yo" de hoy no es mi "yo" de ayer. De ahí que no deberíamos tener miedo a reconocernos diferentes; pese a ello, lo tenemos.

De manera similar, cuando nos pensamos dentro de una nación, como hinchas de un equipo de fútbol, o como miembros de un partido político, o una familia, tendemos a pensar que debemos lealtad incluso cuando sepamos que estamos equivocados. Cuando nos casamos, descubrimos con nuestras parejas diferentes costumbres y nos cuesta convivir; pero con el pasar del tiempo y tras la celebración de enormes tratados de paz, construimos convivencia. En efecto, tenemos tendencia a que la construcción de la alteridad humana se realice desde un concepto unilateral, desde lo occidental o desde lo indígena. Un diálogo para ser respetuoso requiere abrir espacios vivenciales, probar la comida del otro, bailar, vestir, aprender otro idioma. Sólo así podremos entender los chistes ${ }^{39}$ y las normas de las otras culturas. ${ }^{40}$

El diálogo intercultural tiene el reto de liberar tanto a la cultura dominante (de su agresividad inconsciente, de su actitud de superioridad que genera prepotencia y paternalismo), como a la cultura dominada (de su inconsciente agresividad defensiva que generó con los años inferioridad, impotencia, sumisión y resentimiento). Para ello, en lo institucional se necesita que los jueces sean imparciales. Esto implica que estén abiertos a las diferentes culturas, de manera que permitan el diálogo intercultural sincero. El cambio comienza en cada uno de los miembros de una cultura, de su deseo de viajar y de conocer al otro.

\section{Conclusiones}

Los derechos responden a una imagen que tenemos sobre lo que es y debe ser el ser humano. Considerando que somos diferentes y tenemos distintas

\footnotetext{
${ }^{38}$ A sostener del trabajo de dos bolivianos: "Mi 'yo' ha surgido de los 'tú' que me fueron dirigidos: se construye con los lazos que tejo con los demás". Albó, Xavier y Barrios Suvelza, Franz. Por una Bolivia plurinacional e intercultural con autonomías, Programa de la Naciones Unidas para el Desarrollo, Bolivia, 2006.

${ }^{39}$ Por ejemplo cuando vemos el humor japonés en la televisión, si no se comparte la cultura, pueden parecernos agresivos, por tanto, difíciles de entender.

${ }^{40}$ En la Ley de Ayllu, Marcelo Fernández Osco cuenta que en una comunidad indígena se mató a unos delincuentes y luego se mordió sus huesos de forma que no sólo se condenara el cuerpo sino también alma del culpable. FERnÁndez Osco, Marcelo. La Ley del Ayllu: práctica de jach'a justicia y jisk'a justicia en comunidades aymaras, Programa de Investigación Estratégica en Bolivia (PIEB), Bolivia, 2009.
} 
concepciones de nosotros mismos, por una parte los derechos pretenden uniformarnos, pero al mismo tiempo nos distinguen, pues permiten que otros nos acepten diferentes. En efecto, cuando somos mayoría u ocupamos un cargo con poder de decisión, a través de la invocación de lo que entendemos por derechos caemos en la tentación de imponer a los otros lo que consideramos "correcto" o "bueno". Paradójicamente, cuando somos minoría o estamos sometidos a ese poder de decisión, invocando los mismos derechos, procedemos a rechazar lo que nos imponen.

Los derechos se limitan recíprocamente. Así, los derechos colectivos indígenas impiden que un grupo social, étnico, u otro los oprima. Sin embargo, los derechos individuales en un pueblo indígena impiden que un grupo oprima a sus miembros. Por lo tanto, en la relación de lo general y lo particular radica el derecho mínimo que hace a los derechos humanos. El juez tiene una determinada cultura, pero también pertenece a un género mayor: el género humano. Entonces, al interpretar debe proteger simultáneamente los valores de su comunidad - lo particular- y de la raza humana -lo general-.

El carácter "unitario" de un Estado no es sinónimo de homogenizar; no se refiere a la falta de contradicciones, ${ }^{41}$ porque éstas son naturales a la identidad que tenemos cada uno de nosotros, sino que refiere al reto de la complementariedad de lo diverso. ${ }^{42}$ Si pido ser reconocido por los otros, ello automáticamente genera en mí el deber de reconocer a los otros.

La falta de diálogo intercultural sobre el contenido de los derechos humanos provoca que incluso considerando que éstos sean beneficiosos y favorables a sus titulares, no sean aceptados por los mismos si son impuestos y si sus titulares no se convencen sobre su necesidad y justicia. Este aspecto únicamente puede producirse si son resultado de diálogo y no de la fuerza bruta. Cuando engaño a otro -incluso para alcanzar un fin benéfico- provoco desconfianza y resentimiento, que a largo plazo impedirán construir puentes entre las diferentes culturas. El diálogo toma tiempo y recursos económicos, pero sus resultados considerados a largo plazo resultan más sólidos que los resultados emergentes de la imposición.

\footnotetext{
41 "Lo importante en el constitucionalismo intercultural es que si hay diferencias, el objetivo no es un consenso por la uniformidad sino un consenso por sobre el reconocimiento de las diferencias". De Sousa Santos, Boaventura. La reinvención del Estado y el Estado plurinacional. [En linea]. Disponible en: biblioteca.clacso.edu.ar/ar/libros/osal/ osal22/D22SousaSantos.pdf

${ }^{42}$ Como ejemplo de la complementariedad en el mundo indígena aymara, se hace referencia al matrimonio compuesto de un hombre y una mujer. Cada uno de ellos se requiere para formar un matrimonio. Pero ello no implica que en algún momento sus roles de varón y mujer se confundan, pues el hombre seguirá siendo hombre y la mujer cumplirá los roles de mujer (chacha-warmi).
} 